\title{
Vagus Nerve Stimulation as a Potential Adjuvant to Rehabilitation for Post-stroke Motor Speech Disorders
}

\section{OPEN ACCESS}

Edited by:

Tracy M. Centanni, Texas Christian University,

United States

Reviewed by:

Federico Villagra,

Aberystwyth University,

United Kingdom

Paul Yoo,

University of Toronto, Canada

*Correspondence:

Robert A. Morrison

robert.morrison@utdallas.edu

Specialty section:

This article was submitted to

Neuroprosthetics,

a section of the journal

Frontiers in Neuroscience

Received: 27 May 2021

Accepted: 28 July 2021

Published: 19 August 2021

Citation:

Morrison RA, Hays SA and

Kilgard MP (2021) Vagus Nerve

Stimulation as a Potential Adjuvant to Rehabilitation for Post-stroke Motor

Speech Disorders.

Front. Neurosci. 15:715928.

doi: 10.3389/fnins.2021.715928

\begin{abstract}
Robert A. Morrison ${ }^{1,2 *}$, Seth A. Hays ${ }^{1,2,3}$ and Michael P. Kilgard ${ }^{1,2}$
' School of Behavioral and Brain Sciences, University of Texas at Dallas, Richardson, TX, United States, ${ }^{2}$ Texas Biomedical Device Center, University of Texas at Dallas, Richardson, TX, United States, ${ }^{3}$ Erik Jonsson School of Engineering and Computer Science, University of Texas at Dallas, Richardson, TX. United States
\end{abstract}

Stroke often leaves lasting impairments affecting orofacial function. While speech therapy is able to enhance function after stroke, many patients see only modest improvements after treatment. This partial restoration of function after rehabilitation suggests that there is a need for further intervention. Rehabilitative strategies that augment the effects of traditional speech therapy hold promise to yield greater efficacy and reduce disability associated with motor speech disorders. Recent studies demonstrate that brief bursts of vagus nerve stimulation (VNS) can facilitate the benefits of rehabilitative interventions. VNS paired with upper limb rehabilitation enhances recovery of upper limb function in patients with chronic stroke. Animal studies reveal that these improvements are driven by VNS-dependent synaptic plasticity in motor networks. Moreover, preclinical evidence demonstrates that a similar strategy of pairing VNS can promote synaptic reorganization in orofacial networks. Building on these findings, we postulate that VNS-directed orofacial plasticity could target post-stroke motor speech disorders. Here, we outline the rationale for pairing VNS with traditional speech therapy to enhance recovery in the context of stroke of speech motor function. We also explore similar treatments that aim to enhance synaptic plasticity during speech therapy, and how VNS differs from these existing therapeutic strategies. Based on this evidence, we posit that VNS-paired speech therapy shows promise as a means of enhancing recovery after post-stroke motor speech disorders. Continued development is necessary to comprehensively establish and optimize this approach, which has the potential to increase quality of life for the many individuals suffering with these common impairments.

Keywords: vagus nerve stimulation, motor speech disorder, stroke, speech therapy, dysphagia, neuroplasticity, rehabilitation

\section{INTRODUCTION}

Impairments affecting orofacial function are some of the most common lasting deficits after ischemic stroke, second only to hemiparesis. Roughly one third of those who undergo a stroke develop a speech impairment and nearly half will experience dysphagia (Laska et al., 2001; Engelter et al., 2006; Permsirivanich et al., 2009; Flowers et al., 2016; Stipancic et al., 2019). Acquired apraxia 
of speech, the inability to plan movements needed for normal speech production, dysarthria, reduced muscular coordination of speech, and dysphagia, or disrupted swallowing, can have devastating effects on quality of life. Stroke patients with orofacial impairments are twice as likely to require admittance to longterm care facilities (Martino et al., 2005; Smithard et al., 2006; Mitchell et al., 2020). Thus, the development of interventions to improve speech and reduce disability after stroke are of clear clinical importance.

A diverse array of speech-language therapies is used to treat motor speech disorders. Therapy may employ one or several rehabilitative strategies targeting rate and intensity of speech, prosody, and qualities affected by improper muscle control such as phonation and resonance. Course of treatment is commonly assessed based on the patient's individual needs, and depending on severity of injury the clinician may choose to emphasize weak abilities to build strength or focus on coping strategies to circumvent particular deficits. While speech therapy is able to enhance function after stroke, many patients see only modest improvements after treatment (Langhorne et al., 2011; Mitchell et al., 2017), similar to other post-stroke motor rehabilitations (Dobkin, 2004). This partial restoration of function after rehabilitation suggests that there is a need for further intervention. Rehabilitative strategies that augment the effects of traditional speech therapy hold promise in reducing the disability associated with motor speech disorders, possibly enhancing recovery further (Ludlow et al., 2008). Here, we outline the rationale for pairing vagus nerve stimulation (VNS) with traditional speech therapy to enhance synaptic plasticity and improve recovery from post-stroke motor speech disorders.

\section{PLASTICITY UNDERLIES FUNCTIONAL IMPROVEMENTS OF MOTOR SPEECH CONTROL RECOVERY}

Neuroplasticity allows the brain to reorganize speech circuits disrupted by stroke and is a driving force behind recovery from motor speech disorders (Hartwigsen and Saur, 2019; Wilson and Schneck, 2021). Though speech production is heavily lateralized to the left hemisphere, increases in neuroplasticity during speech therapy can shift speech processing toward the right hemisphere (Anglade et al., 2014; Wan et al., 2014). Moreover, areas directly adjacent to the site of injury can undergo reorganization after therapy (Barritt and Smithard, 2009; Schlaug et al., 2009; Fridriksson et al., 2012). Plasticity in orofacial motor areas have been implicated in increases in function after speech therapy as well (Ludlow et al., 2008; Avivi-Arber et al., 2010), suggesting that plasticity of circuits directly involved in speech production plays a significant role in mediating recovery. These increases in neuroplasticity are thought to aid in the bypassing of injured circuits contributing to motor speech impairment, allowing the nervous system to compensate for loss of function (Khedr and Abo-Elfetoh, 2010; Kumar et al., 2011; Thiel et al., 2013). Given the importance of neuroplasticity underlying speech therapy and the incomplete recovery many patients experience after undergoing treatment, it is reasonable to conclude that interventions that further enhance the neuroplasticity produced by speech therapy could lead to greater functional outcomes.

\section{VAGUS NERVE STIMULATION}

Vagus nerve stimulation has emerged as a method of enhancing rehabilitative outcomes for a wide range of neurological injuries, including stroke (Khodaparast et al., 2013, 2014; Hays et al., 2014b, 2016; Dawson et al., 2016, 2021; Pruitt et al., 2016, 2021; Ganzer et al., 2018; Kimberley et al., 2018; Meyers et al., 2018; Table 1). VNS increases the effects of rehabilitation through targeted enhancement of synaptic plasticity in central networks after injury. Electrical stimulation of the vagus nerve immediately enhances neuromodulatory function. Bursts of VNS rapidly activate the noradrenergic locus coeruleus (LC) and cholinergic nucleus basalis (NB), two major neuromodulatory centers in the brain (Dorr, 2006; Roosevelt et al., 2006; Nichols et al., 2011; Hulsey et al., 2016, 2017, 2019). Coincident release of these proplasticity neuromodulators coupled with neural activity related to rehabilitation facilitates synaptic plasticity in task-specific activated circuits (Dorr, 2006; Roosevelt et al., 2006; Seol et al., 2007; He et al., 2015; Hulsey et al., 2017).

\section{VAGUS NERVE STIMULATION ENHANCES PLASTICITY AND RECOVERY IN MOTOR DYSFUNCTION}

Vagus nerve stimulation enhances cortical representations related to a variety of motor activities. Stimulation of the vagus nerve paired with movement during motor training increases synaptic plasticity in activated circuits, selectively expanding cortical representations of the muscles active at the time of stimulation (Porter et al., 2012; Hulsey et al., 2016, 2019; Meyers et al., 2018; Morrison et al., 2019; Tseng et al., 2020). VNS-mediated synaptic plasticity also takes place in sub-cortical structures throughout task-related circuits (Ganzer et al., 2018; Borland et al., 2019). This targeted-enhancement of plasticity has proven useful in augmenting the effects of motor rehabilitation (Table 1). VNSpaired stroke upper limb rehabilitation significantly enhances motor recovery compared to traditional rehabilitation alone in rats (Khodaparast et al., 2013, 2016; Hays et al., 2014a,b, 2016). Furthermore, three clinical trials have now demonstrated that VNS-paired stroke rehabilitation significantly enhances functional recovery in humans, as indicated by increases in common clinical measures of upper limb motor function, including the Upper Extremity Fugl-Meyer Assessment and the Wolf Motor Function Test (Dawson et al., 2016, 2021; Kimberley et al., 2018).

The timing and electrical parameters of VNS appear to be of particular importance. VNS is able to potentiate circuits activated within a roughly $2 \mathrm{~s}$ window after stimulation occurs (Ganzer et al., 2018), meaning stimulation is most effective when paired coincident with or immediately after movements during rehabilitation. Electrical parameters of stimulation are also a critical determinant of the magnitude of VNS effects. Short half 
TABLE 1 | Vagus nerve stimulation (VNS) enhances a wide range of rehabilitative therapies.

\begin{tabular}{|c|c|c|c|c|}
\hline Impairment & Cause & Intervention & Animal evidence & Clinical evidence \\
\hline \multirow[t]{4}{*}{ Hemiparesis } & Stroke & VNS + motor rehabilitation & $\begin{array}{c}\text { Khodaparast et al., 2013, 2014; Hays } \\
\text { et al., 2014b, 2016; Meyers et al., } \\
\text { 2018; Pruitt et al., } 2021\end{array}$ & $\begin{array}{l}\text { Dawson et al., 2016, 2021; } \\
\quad \text { Kimberley et al., } 2018\end{array}$ \\
\hline & Spinal cord injury & VNS + motor rehabilitation & $\begin{array}{l}\text { Ganzer et al., 2018; Darrow et al., } \\
\text { 2020b }\end{array}$ & Kilgard et al., 2021 \\
\hline & Traumatic brain injury & VNS + motor rehabilitation & Pruitt et al., 2016 & \\
\hline & Neuropathy & VNS + motor rehabilitation & Meyers et al., 2019 & \\
\hline Auditory & Tinnitus & VNS + auditory therapy & Engineer et al., 2011, 2015 & $\begin{array}{l}\text { De Ridder et al., 2014, 2015; } \\
\text { Tyler et al., 2017; Vanneste et al., } \\
2017\end{array}$ \\
\hline \multirow[t]{2}{*}{ Somatosensory } & Stroke & VNS + tactile rehabilitation & & Kilgard et al., 2018 \\
\hline & Neuropathy & VNS + sensory rehabilitation & $\begin{array}{l}\text { Meyers et al., 2019; Darrow et al., } \\
\text { 2020a, } 2021\end{array}$ & \\
\hline Anxiety & $\begin{array}{l}\text { Post-traumatic stress } \\
\text { disorder }\end{array}$ & $\begin{array}{c}\text { VNS }+ \text { prolonged exposure } \\
\text { therapy }\end{array}$ & $\begin{array}{l}\text { Pena et al., 2014; Noble et al., 2017; } \\
\text { Souza et al., } 2020\end{array}$ & $\begin{array}{l}\text { George et al., 2008; Kilgard et al., } \\
2020\end{array}$ \\
\hline
\end{tabular}

second bursts of $0.8 \mathrm{~mA}, 30 \mathrm{~Hz}$ stimulation with a $100 \mu \mathrm{s}$ pulse width appear to be optimal for VNS-mediated synaptic plasticity and enhancement of recovery, and deviations from this stimulation paradigm often lessen or abolish VNS-mediated effects (Buell et al., 2018; Loerwald et al., 2018; Morrison et al., 2020, 2021; Pruitt et al., 2021).

\section{VAGUS NERVE STIMULATION IMPLANTATION, SAFETY, AND TOLERABILITY}

Vagus nerve stimulation is an Frenchay Dysarthria Assessment (FDA)-approved therapy used to decrease symptoms of treatment resistant epilepsy and depression. VNS implantation consists of a pulse generator implanted near the clavicle, and two leads deliver electrical stimulation to a nerve cuff implanted in the neck around the left cervical branch of the vagus nerve. VNS devices have been implanted in over 1,00,000 people worldwide, and VNS is generally regarded as a safe and well-tolerated treatment (Yang and Phi, 2019).

The most common side effects arising from device implantation are acute vocal cord paresis ( $1 \%$ of patients) and acute lower facial weakness (1\% of patients) (Ben-Menachem et al., 2015). As with any invasive procedure, risk of infection is also possible (3-6\% of patients), and in some cases, these events result in device removal (Ben-Menachem et al., 2015; Yang and Phi, 2019). There have been recent efforts to minimize invasiveness by wirelessly powering the implanted nerve cuff, foregoing the use of an implanted pulse generator (Sivaji et al., 2019; Kilgard et al., 2020, 2021), which could conceivably decrease risk of infection in the future. Adverse events (AEs) arising from stimulation of the vagus nerve can include acute voice alteration, cough, dyspnea, paresthesia, headache, and neck pain (Ben-Menachem et al., 2015), however, these symptoms are most often present during the initial period of stimulation and decline over time (Morris and Mueller, 1999). It is also noteworthy that the duty cycle and cumulative amount of stimulation patients traditionally receive for treatment of epilepsy and depression is far greater than that of patients undergoing VNS-therapy paired with rehabilitation (Dawson et al., 2016, 2021; Kimberley et al., 2018), which could significantly decreases the magnitude or prevalence of AEs arising from stimulation.

Based on the known side effect profile of VNS, it is possible that some AEs associated with VNS, including acute voice alteration, cough, and similar side effects, could interfere with speech therapy. However, some preventative measures could be taken to minimize risk of this interference. First, because adverse effects of related to stimulation normally resolve over time, any effects that disrupt speech therapy during the beginning stages of treatment may subside as treatment progresses. Second, for stimulation-related AEs that prove too disruptive early in speech therapy may be circumvented through habituation. VNS has been shown to treat stroke in chronic stages, years after initial injury and onset of deficits (Dawson et al., 2016, 2021; Kimberley et al., 2018). Because the start of VNS therapy does not appear to be time sensitive, it is possible that patients with newly implanted devices could be habituated for a number of weeks to stimulation before speech therapy begins, allowing for the minimization of any AEs.

\section{ADAPTING VNS THERAPY FOR UPPER LIMB DYSFUNCTION TO TREAT POST-STROKE MOTOR SPEECH DISORDERS}

Vagus nerve stimulation paired with upper limb rehabilitation enhances upper limb function after stroke (Dawson et al., 2016, 2021; Kimberley et al., 2018). Given the commonalities between limb motor control and speech motor control rehabilitation, it has been suggested that principles of motor learning and rehabilitation often applied to upper limb treatment could be applied to speech therapy as well (Ludlow et al., 2008; Maas et al., 2008; Grimme et al., 2011). Recent work demonstrates that VNS can significantly enhance synaptic plasticity in corticobulbar circuits mediating orofacial movement. Repeatedly pairing VNS with jaw movement increases the area of motor cortex that evokes 
jaw movements via intracortical microstimulation (Morrison et al., 2020, 2021). Because VNS enhances recovery from upper limb dysfunction by increasing synaptic plasticity in corticospinal upper limb circuits, enhancement of speech therapy for post-stroke motor speech disorders such as apraxia and dysarthria could similarly be realized via VNS-mediated plasticity in corticobulbar circuits involved in speech production. This possibility is further supported by the fact that plasticity in cortical orofacial areas is already implicated in recovery from motor speech dysfunction (Ludlow et al., 2008; Avivi-Arber et al., 2010), suggesting VNS could prove a useful adjuvant to enhance the effects of various traditional speech therapy interventions after stroke.

While there are certainly commonalties between speech motor control and limb motor control rehabilitation, there are significant differences between orofacial and limb biomechanics, their anatomical networks, and the neural activity governing their movement. Speech motor acts have large, variable degrees of freedom due to their complexity, and compared to motor acts of the limbs, have much faster rates of production (Grimme et al., 2011). Speech production is complex even compared to upper limb movements and is governed by a diverse array of orofacial and laryngeal muscles that are even further modulated by changes in respiration and airflow (Kent, 2004). Though speech motor acts and upper limb movements may vary in anatomy and complexity, it is possible that VNS could overcome these differences due to its known ability to potentiate and reorganize circuits in a diverse array of networks. For example, VNS-paired training can direct plasticity in cortical and subcortical auditory networks related to sound perception (Borland et al., 2019), hippocampal and amygdala networks related to memory and anxiety (Zuo et al., 2007; Pena et al., 2014), at multiple points along the corticospinal pathway mediating limb movement (Ganzer et al., 2018), and in corticobulbar pathways mediating jaw movement (Morrison et al., 2020). That VNS can enhance plasticity in such a diverse array of systems suggests it could possibly potentiate speech networks in a similar manner.

Using a paradigm similar to that of existing VNS-paired upper limb stroke rehabilitation (Dawson et al., 2016; Kimberley et al., 2018) could allow for pairing of VNS with multiple speech therapy techniques. VNS paired with specific exercises could allow for targeted enhancement of orofacial circuits involved in specific deficits, enhancing recovery. Under this rehabilitation paradigm, the therapist leading the speech therapy session would activate the patient's VNS implant via a wireless remote (Figure 1). The therapist would conduct speech therapy normally, triggering VNS when the patient is performing speech therapy exercises, emphasizing moments they view as conducive to recovery. This timed, performance-dependent application of VNS strives to reorganize and strengthen the circuits activated during speech therapy that mediate recovery, enhancing the effects of rehabilitation. Clinical efficacy of VNS-paired speech therapy could be quantitatively determined using a mix of deficitspecific assessments such as the Apraxia of Speech Rating Scale (ASRS; Strand et al., 2014), the FDA-2 (Enderby, 1980), and quality of life observations using activity of daily living (ADL) and the Barthal ADL Index (Geusgens et al., 2006). Using VNS, it is possible that rehabilitative exercises that are already evidenced to promote recovery could be further enhanced, such as dysarthria-specific oromotor exercises (Mackenzie et al., 2014), articulatory feedback training for apraxia of speech (Katz and McNeil, 2010; Ballard et al., 2015), and respiratory muscle training for those with post-stroke respiratory weakness (Menezes et al., 2016).

\section{VAGUS NERVE STIMULATION AS AN ALTERNATIVE TO PREVIOUSLY STUDIED NEUROMODULATORY STRATEGIES IN SPEECH THERAPY}

Increasing neuroplasticity during speech therapy to enhance its effects has long been considered a promising treatment. Pharmacological augmentation of speech therapy has been proposed as a means of increasing the magnitude of neuroplasticity during treatment to gain better recovery outcomes (Berthier, 2005). However, clinical investigation of speech therapy paired with a wide range of drugs affecting neuromodulatory systems has generally shown mixed effects on recovery (McNeil et al., 1997; Noble and Benfield, 1998; Berthier, 2005), further complicating the use of pharmacologically augmented speech therapy. While a number of these drugs of interest may enhance neuroplasticity, many have contraindications, particularly in those with underlying cardiovascular issues that can contribute to stroke. Many of these drugs activate neuromodulatory systems similar to those activated by VNS, but one critical difference is the timing of neuromodulation. The systemic nature of drugs do not lend to potentiation of circuits contributing to recovery from speech disorders, but instead, lead to a global, sustained activation of neuromodulatory systems. Alternatively, VNS-paired rehabilitation accounts for this lack of temporal specificity by only increasing neuromodulator levels transiently, allowing for the targeting of specific neural circuits mediating recovery.

Another approach to the problem of temporal specificity in neuromodulatory activity, transcranial direct current stimulation (tDCS; Fridriksson et al., 2011; Hamilton et al., 2011; Doeltgen et al., 2015; Elsner et al., 2015; Turkeltaub et al., 2016) and transcranial magnetic stimulation (TMS; Hamilton et al., 2011; Naeser et al., 2012) have been used in conjunction with speech therapy with more promising, yet still mixed outcomes. While timed bursts of tDCS and TMS may solve for the lack of temporal specificity seen in pharmacological augmentation of speech therapy, these treatments locally activate glutamatergic and GABAergic neurons (Medeiros et al., 2012; Cirillo et al., 2017), which may actively interfere with circuits mediating motor function. VNS, however, only increases neuromodulatory function and does not interfere with ongoing neural spiking (Hulsey et al., 2016, 2017, 2019; Morrison et al., 2019, 2020). The temporal specificity of VNS positions it as a promising alternative to drugs, tDCS, and TMS in treating motor speech dysfunction after stroke. 


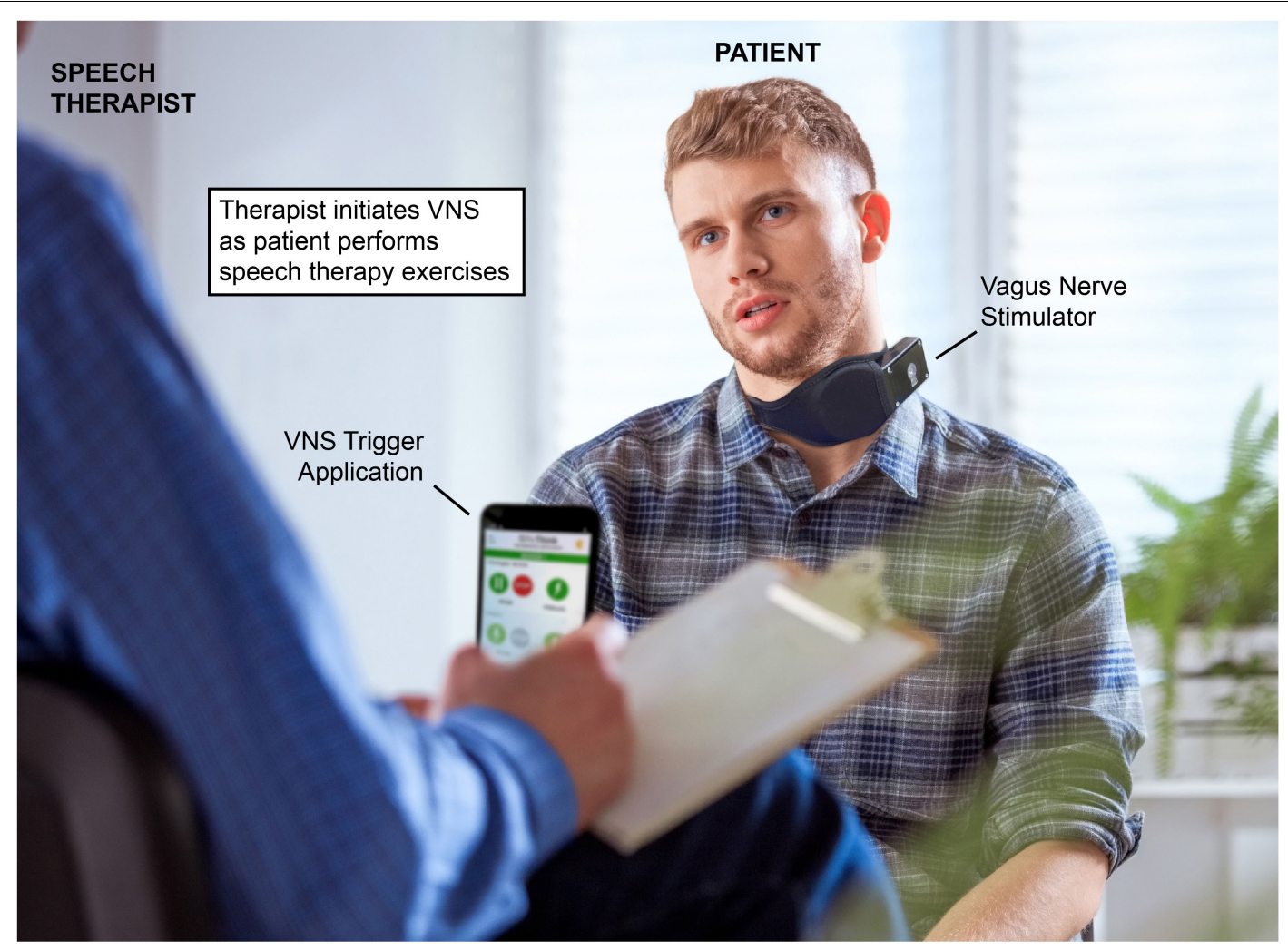

FIGURE 1 | Example of vagus nerve stimulation (VNS) paired speech therapy. A patient with a VNS implant performs speech therapy exercises. The speech therapist initiates VNS via a mobile application at moments the therapist deems conducive to the patient's recovery. The mobile device used by the therapist activates the power control module, which wirelessly powers the implanted vagal nerve cuff. Reproduced with permission from www.istockphoto.com.

\section{APPLICATIONS FOR VNS-PAIRED TREATMENT OF DYSPHAGIA}

Post-stroke dysphagia is another commonly experienced disability, affecting approximately $50-75 \%$ of patients (Mann et al., 1999; Martino et al., 2005; Singh, 2006; Barritt and Smithard, 2009; Stipancic et al., 2019). While post-stroke dysphagia is often acute, resolving within a month after injury, up to $40 \%$ of patients can still display disrupted swallowing a year after onset (Terré and Mearin, 2009). Chronic dysphagia increases risk for aspiration pneumonia, admittance to long-term care facilities, and death (Martino et al., 2005; Smithard et al., 2006). While behavioral mitigation strategies and diets limiting food consistency are common treatment prescriptions, these are often ineffective at improving long-term outcomes (Carnaby et al., 2006). Similar to recovery from apraxia of speech, plasticity in orofacial motor areas in cortex appears to be a determinant of recovery of function in post-stroke dysphagia. After stroke, increases in oropharyngeal representation in the contralesional hemisphere accompany recovery from dysphagia (Hamdy et al., 1998; Barritt and Smithard, 2009). Given the high comorbidity of post-stroke speech apraxia and dysphagia, their similarities in underlying pathologies, and their overlap in therapeutic strategies, VNS may prove an effective adjuvant to dysphagia treatment, such as oromotor exercises as well.

\section{CONCLUSION}

Vagus nerve stimulation has emerged as a method of enhancing rehabilitative outcomes for a wide range of neurological disorders. Here, we suggest pairing VNS with traditional speech therapy to enhance recovery from post-stroke speech motor dysfunction. We outline clinical success of VNS-paired physical rehabilitation after stroke, which demonstrates that VNS can induce plasticity in task-activated motor systems, enhancing patient recovery outcomes. Furthermore, we summarize the observations that VNS can enhance plasticity in orofacial networks when paired with jaw movement, which supports its use as a potential adjuvant to speech therapy in treating motor speech dysfunction. Based on this evidence, we believe VNSpaired speech therapy shows promise as a means of enhancing recovery after post-stroke motor speech disorders, and future study of this new treatment has potential to increase function, and subsequently quality of life for the many suffers of these common conditions.

\section{AUTHOR CONTRIBUTIONS}

RM drafted the manuscript. All authors contributed to the manuscript revision and approved the submitted version. 


\section{FUNDING}

This work was supported by the National Institutes of Health R01NS094384 and R01NS103803, and the DARPA BTO Targeted Neuroplasticity Training (TNT) program under the auspices of Tristan McClure-Begley through the Space and Naval Warfare Systems Center, Pacific Grant/Contract No. N66001-17-2-4011.

\section{REFERENCES}

Anglade, C., Thiel, A., and Ansaldo, A. I. (2014). The complementary role of the cerebral hemispheres in recovery from aphasia after stroke: a critical review of literature. Brain Injury 28, 138-145. doi: 10.3109/02699052.2013. 859734

Avivi-Arber, L., Lee, J.-C., Yao, D., Adachi, K., and Sessle, B. J. (2010). Neuroplasticity of face sensorimotor cortex and implications for control of orofacial movements. Jpn. Dent. Sci. Rev. 46, 132-142. doi: 10.1016/j.jdsr.2009. 11.007

Ballard, K. J., Wambaugh, J. L., Duffy, J. R., Layfield, C., Maas, E., Mauszycki, S., et al. (2015). Treatment for acquired apraxia of speech: a systematic review of intervention research between 2004 and 2012. Am. J. Speech Lang. Pathol. 24, 316-337. doi: 10.1044/2015_AJSLP-14-0118

Barritt, A. W., and Smithard, D. G. (2009). Role of cerebral cortex plasticity in the recovery of swallowing function following dysphagic stroke. Dysphagia 24, 83-90. doi: 10.1007/s00455-008-9162-3

Ben-Menachem, E., Revesz, D., Simon, B. J., and Silberstein, S. (2015). Surgically implanted and non-invasive vagus nerve stimulation: a review of efficacy, safety and tolerability. Eur. J. Neurol. 22, 1260-1268. doi: 10.1111/ene.12629

Berthier, M. L. (2005). Poststroke aphasia. Drugs Aging 22, 163-182. doi: 10.2165/ 00002512-200522020-00006

Borland, M. S., Vrana, W. A., Moreno, N. A., Fogarty, E. A., Buell, E. P., Vanneste, S., et al. (2019). Pairing vagus nerve stimulation with tones drives plasticity across the auditory pathway. J. Neurophysiol. 122, 659-671. doi: 10.1152/jn. 00832.2018

Buell, E. P., Loerwald, K. W., Engineer, C. T., Borland, M. S., Buell, J. M., Kelly, C. A., et al. (2018). Cortical map plasticity as a function of vagus nerve stimulation rate. Brain Stimul. 11, 1218-1224. doi: 10.1016/j.brs.2018.07.045

Carnaby, G., Hankey, G. J., and Pizzi, J. (2006). Behavioural intervention for dysphagia in acute stroke: a randomised controlled trial. Lancet Neurol. 5, 31-37. doi: 10.1016/S1474-4422(05)70252-0

Cirillo, G., Di Pino, G., Capone, F., Ranieri, F., Florio, L., Todisco, V., et al. (2017). Neurobiological after-effects of non-invasive brain stimulation. Brain Stimul. 10, 1-18. doi: 10.1016/j.brs.2016.11.009

Darrow, M. J., Mian, T. M., Torres, M., Haider, Z., Danaphongse, T., Rennaker, R. L., et al. (2020a). Restoration of somatosensory function by pairing vagus nerve stimulation with tactile rehabilitation. Ann. Neurol. 87, 194-205. doi: 10.1002/ana.25664

Darrow, M. J., Mian, T. M., Torres, M., Haider, Z., Danaphongse, T., Seyedahmadi, A., et al. (2021). The tactile experience paired with vagus nerve stimulation determines the degree of sensory recovery after chronic nerve damage. Behav. Brain Res. 396:112910. doi: 10.1016/j.bbr.2020.112910

Darrow, M. J., Torres, M., Sosa, M. J., Danaphongse, T. T., Haider, Z., Rennaker, R. L., et al. (2020b). Vagus nerve stimulation paired with rehabilitative training enhances motor recovery after bilateral spinal cord injury to cervical forelimb motor pools. Neurorehabil. Neural Repair 34, 200-209. doi: 10.1177/ 1545968319895480

Dawson, J., Liu, C. Y., Francisco, G. E., Cramer, S. C., Wolf, S. L., Dixit, A., et al. (2021). Vagus nerve stimulation paired with rehabilitation for upper limb motor function after ischaemic stroke (VNS-REHAB): a randomised, blinded, pivotal, device trial. Lancet 397, 1545-1553. doi: 10.1016/S0140-6736(21)00475-X

Dawson, J., Pierce, D., Dixit, A., Kimberley, T. J., Robertson, M., Tarver, B., et al. (2016). Safety, feasibility, and efficacy of vagus nerve stimulation paired with upper-limb rehabilitation after ischemic stroke. Stroke 47, 143-150. doi: 10. 1161/STROKEAHA.115.010477

De Ridder, D., Kilgard, M., Engineer, N., and Vanneste, S. (2015). Placebocontrolled vagus nerve stimulation paired with tones in a patient with refractory

\section{ACKNOWLEDGMENTS}

We would like to thank Adrianna Shembel, William Katz, Yune Lee, and Bharath Chandrasekaran for their insight and feedback during preparation of this manuscript. We would also like to thank Nikki Simmons for help with artwork.

tinnitus: a case report. Otol. Neurotol. 36, 575-580. doi: 10.1097/MAO. 0000000000000704

De Ridder, D., Vanneste, S., Engineer, N. D., and Kilgard, M. P. (2014). Safety and efficacy of vagus nerve stimulation paired with tones for the treatment of tinnitus: a case series. Neuromodul. Technol. Neural Interf. 17, 170-179. doi: $10.1111 /$ ner.12127

Dobkin, B. H. (2004). Strategies for stroke rehabilitation. Lancet Neurol. 3, 528-536. doi: 10.1016/S1474-4422(04)00851-8

Doeltgen, S. H., Bradnam, L. V., Young, J. A., and Fong, E. (2015). Transcranial non-invasive brain stimulation in swallowing rehabilitation following stroke a review of the literature. Physiol. Behav. 143, 1-9. doi: 10.1016/j.physbeh.2015. 02.025

Dorr, A. E. (2006). Effect of vagus nerve stimulation on serotonergic and noradrenergic transmission. J. Pharmacol. Exp. Ther. 318, 890-898. doi: 10. 1124/jpet.106.104166

Elsner, B., Kugler, J., Pohl, M., and Mehrholz, J. (2015). Transcranial direct current stimulation (tDCS) for improving aphasia in patients with aphasia after stroke. Cochrane Datab. Syst. Rev. 5:CD009760. doi: 10.1002/14651858.CD009760. pub3

Enderby, P. (1980). Frenchay dysarthria assessment. Int. J. Lang. Commun. Disord. 15, 165-173. doi: 10.3109/13682828009112541

Engelter, S. T., Gostynski, M., Papa, S., Frei, M., Born, C., Ajdacic-Gross, V., et al. (2006). Epidemiology of aphasia attributable to first ischemic stroke. Stroke 37, 1379-1384. doi: 10.1161/01.STR.0000221815.64093.8c

Engineer, C. T., Engineer, N. D., Riley, J. R., Seale, J. D., and Kilgard, M. P. (2015) Pairing speech sounds with vagus nerve stimulation drives stimulus-specific cortical plasticity. Brain Stimul. 8, 637-644. doi: 10.1016/j.brs.2015.01.408

Engineer, N. D., Riley, J. R., Seale, J. D., Vrana, W. A., Shetake, J. A., Sudanagunta, S. P., et al. (2011). Reversing pathological neural activity using targeted plasticity. Nature 470, 101-104. doi: 10.1038/nature09656

Flowers, H. L., Skoretz, S. A., Silver, F. L., Rochon, E., Fang, J., Flamand-Roze, C., et al. (2016). ). Poststroke aphasia frequency, recovery, and outcomes: a systematic review and meta-analysis. Arch. Phys. Med. Rehabil. 97, 2188 2201.e8. doi: 10.1016/j.apmr.2016.03.006

Fridriksson, J., Richardson, J. D., Baker, J. M., and Rorden, C. (2011). Transcranial direct current stimulation improves naming reaction time in fluent aphasia. Stroke 42, 819-821. doi: 10.1161/STROKEAHA.110.600288

Fridriksson, J., Richardson, J. D., Fillmore, P., and Cai, B. (2012). Left hemisphere plasticity and aphasia recovery. Neuroimage 60, 854-863. doi: 10.1016/j. neuroimage.2011.12.057

Ganzer, P. D., Darrow, M. J., Meyers, E. C., Solorzano, B. R., Ruiz, A. D., Robertson, N. M., et al. (2018). Closed-loop neuromodulation restores network connectivity and motor control after spinal cord injury. eLife 7, 1-19. doi: 10.7554/eLife.32058

George, M. S., Ward, H. E., Ninan, P. T., Pollack, M., Nahas, Z., Anderson, B., et al. (2008). A pilot study of vagus nerve stimulation (VNS) for treatment-resistant anxiety disorders. Brain Stimul. 1, 112-121. doi: 10.1016/j.brs.2008.02.001

Geusgens, C., van Heugten, C., Donkervoort, M., van den Ende, E., Jolles, J., and van den Heuvel, W. (2006). Transfer of training effects in stroke patients with apraxia: an exploratory study. Neuropsychol. Rehabil. 16, 213-229. doi: $10.1080 / 09602010500172350$

Grimme, B., Fuchs, S., Perrier, P., and Schöner, G. (2011). Limb versus speech motor control: a conceptual review. Motor Control 15, 5-33. doi: 10.1123/mcj. 15.1 .5

Hamdy, S., Aziz, Q., Rothwell, J. C., Power, M., Singh, K. D., Nicholson, D. A., et al. (1998). Recovery of swallowing after dysphagic stroke relates to functional reorganization in the intact motor cortex. Gastroenterology 115, 1104-1112. doi: 10.1016/s0016-5085(98)70081-2 
Hamilton, R. H., Chrysikou, E. G., and Coslett, B. (2011). Mechanisms of aphasia recovery after stroke and the role of noninvasive brain stimulation. Brain Lang. 118, 40-50. doi: 10.1016/j.bandl.2011.02.005

Hartwigsen, G., and Saur, D. (2019). Neuroimaging of stroke recovery from aphasia - Insights into plasticity of the human language network. Neuroimage 190, 14-31. doi: 10.1016/j.neuroimage.2017.11.056

Hays, S. A., Khodaparast, N., Hulsey, D. R., Ruiz, A., Sloan, A. M., Rennaker, R. L., et al. (2014a). Vagus nerve stimulation during rehabilitative training improves functional recovery after intracerebral hemorrhage. Stroke 45, 3097-3100. doi: 10.1161/STROKEAHA.114.006654

Hays, S. A., Khodaparast, N., Ruiz, A., Sloan, A. M., Hulsey, D. R., Rennaker, R. L., et al. (2014b). The timing and amount of vagus nerve stimulation during rehabilitative training affect poststroke recovery of forelimb strength. NeuroReport 25, 682-688. doi: 10.1097/WNR.0000000000000154

Hays, S. A., Ruiz, A., Bethea, T., Khodaparast, N., Carmel, J. B., Rennaker, R. L., et al. (2016). Vagus nerve stimulation during rehabilitative training enhances recovery of forelimb function after ischemic stroke in aged rats. Neurobiol. Aging 43, 111-118. doi: 10.1016/j.neurobiolaging.2016.03.030

He, K., Huertas, M., Hong, S. Z., Tie, X. X., Hell, J. W., Shouval, H., et al. (2015). Distinct eligibility traces for LTP and LTD in cortical synapses. Neuron 88, 528-538. doi: 10.1016/j.neuron.2015.09.037

Hulsey, D. R., Hays, S. A., Khodaparast, N., Ruiz, A., Das, P., Rennaker, R. L., et al. (2016). Reorganization of motor cortex by vagus nerve stimulation requires cholinergic innervation. Brain Stimul. 9, 174-181. doi: 10.1016/j.brs.2015.12. 007

Hulsey, D. R., Riley, J. R., Loerwald, K. W., Rennaker, R. L., Kilgard, M. P., and Hays, S. A. (2017). Parametric characterization of neural activity in the locus coeruleus in response to vagus nerve stimulation. Exp. Neurol. 289, 21-30. doi: 10.1016/j.expneurol.2016.12.005

Hulsey, D. R., Shedd, C. M., Sarker, S. F., Kilgard, M. P., and Hays, S. A. (2019). Norepinephrine and serotonin are required for vagus nerve stimulation directed cortical plasticity. Exp. Neurol. 320:112975. doi: 10.1016/j.expneurol. 2019.112975

Katz, W. F., and McNeil, M. R. (2010). Studies of articulatory feedback treatment for apraxia of speech based on electromagnetic articulography. Perspect. Neurophysiol. Neurogenic Speech Lang. Disord. 20, 73-79. doi: 10.1044/nnsld20. 3.73

Kent, R. D. (2004). The uniqueness of speech among motor systems. Clin. Linguist. Phonet. 18, 495-505. doi: 10.1080/02699200410001703600

Khedr, E. M., and Abo-Elfetoh, N. (2010). Therapeutic role of rTMS on recovery of dysphagia in patients with lateral medullary syndrome and brainstem infarction. J. Neurol. Neurosurg. Psychiatry 81, 495-499. doi: 10.1136/jnnp.2009. 188482

Khodaparast, N., Hays, S. A., Sloan, A. M., Fayyaz, T., Hulsey, D. R., Rennaker, R. L., et al. (2014). Vagus nerve stimulation delivered during motor rehabilitation improves recovery in a rat model of stroke. Neurorehabil. Neural Repair 28, 698-706. doi: 10.1177/1545968314521006

Khodaparast, N., Hays, S. A., Sloan, A. M., Hulsey, D. R., Ruiz, A., Pantoja, M., et al. (2013). Vagus nerve stimulation during rehabilitative training improves forelimb strength following ischemic stroke. Neurobiol. Dis. 60, 80-88. doi: 10.1016/j.nbd.2013.08.002

Khodaparast, N., Kilgard, M. P., Casavant, R., Ruiz, A., Qureshi, I., Ganzer, P. D., et al. (2016). Vagus nerve stimulation during rehabilitative training improves forelimb recovery after chronic ischemic stroke in rats. Neurorehabil. Neural Repair 30, 676-684. doi: 10.1177/1545968315616494

Kilgard, M. P., Hays, S. A., Rennaker, R. L., Wigginton, J. G., Foreman, M., Powers, M., et al. (2020). Targeted Plasticity Therapy for Posttraumatic Stress Disorder. Available online at: https://clinicaltrials.gov/ct2/show/NCT04064762 (accessed December 16, 2020).

Kilgard, M. P., Rennaker, R. L., Alexander, J., and Dawson, J. (2018). Vagus nerve stimulation paired with tactile training improved sensory function in a chronic stroke patient. NeuroRehabilitation 42, 159-165. doi: 10.3233/NRE-172273

Kilgard, M. P., Rennaker, R. L., Hays, S. A., Wigginton, J. G., Hamilton, R., Foreman, M., et al. (2021). Targeted Plasticity Therapy for Upper Limb Rehabilitation in Spinal Cord Injuries. Available online at: https://clinicaltrials. gov/ct2/show/NCT04288245 (accessed February 15, 2021).

Kimberley, T. J., Pierce, D., Prudente, C. N., Francisco, G. E., Yozbatiran, N., Smith, P., et al. (2018). Vagus nerve stimulation paired with upper limb rehabilitation after chronic stroke: a blinded randomized pilot study. Stroke 49, 2789-2792. doi: 10.1161/STROKEAHA.118.022279

Kumar, S., Wagner, C. W., Frayne, C., Zhu, L., Selim, M., Feng, W., et al. (2011). Noninvasive brain stimulation may improve stroke-related dysphagia. Stroke 42, 1035-1040. doi: 10.1161/STROKEAHA.110.602128

Langhorne, P., Bernhardt, J., and Kwakkel, G. (2011). Stroke rehabilitation. Lancet 377, 1693-1702. doi: 10.1016/S0140-6736(11)60325-5

Laska, A. C., Hellblom, A., Murray, V., Kahan, T., and Von Arbin, M. (2001). Aphasia in acute stroke and relation to outcome. J. Int. Med. 249, 413-422. doi: 10.1046/j.1365-2796.2001.00812.x

Loerwald, K. W., Borland, M. S., Rennaker, R. L., Hays, S. A., and Kilgard, M. P. (2018). The interaction of pulse width and current intensity on the extent of cortical plasticity evoked by vagus nerve stimulation. Brain Stimul. 11, 271-277. doi: 10.1016/j.brs.2017.11.007

Ludlow, C. L., Hoit, J., Kent, R., Ramig, L. O., Shrivastav, R., Strand, E., et al. (2008). Translating principles of neural plasticity into research on speech motor control recovery and rehabilitation. J. Speech Lang. Hear. Res. 51, S240-S258. doi: 10.1044/1092-4388(2008/019

Maas, E., Robin, D. A., Austermann Hula, S. N., Freedman, S. E., Wulf, G., Ballard, K. J., et al. (2008). Principles of motor learning in treatment of motor speech disorders. Am. J. Speech Lang. Pathol. 17, 277-298. doi: 10.1044/10580360(2008/025)

Mackenzie, C., Muir, M., Allen, C., and Jensen, A. (2014). Non-speech oro-motor exercises in post-stroke dysarthria intervention: a randomized feasibility trial. Int. J. Lang. Commun. Disord. 49, 602-617. doi: 10.1111/1460-6984.12096

Mann, G., Hankey, G. J., and Cameron, D. (1999). Swallowing function after stroke. Stroke 30, 744-748. doi: 10.1161/01.STR.30.4.744

Martino, R., Foley, N., Bhogal, S., Diamant, N., Speechley, M., and Teasell, R. (2005). Dysphagia after stroke. Stroke 36, 2756-2763. doi: 10.1161/01.STR. 0000190056.76543.eb

McNeil, M. R., Doyle, P. J., Spencer, K. A., Goda, A. J., Flores, D., and Small, S. L. (1997). A double-blind, placebo-controlled study of pharmacological and behavioural treatment of lexical-semantic deficits in aphasia. Aphasiology 11, 385-400. doi: 10.1080/02687039708248479

Medeiros, L. F., de Souza, I. C. C., Vidor, L. P., de Souza, A., Deitos, A., Volz, M. S., et al. (2012). Neurobiological effects of transcranial direct current stimulation: a review. Front. Psychiatry 3:110. doi: 10.3389/fpsyt.2012.00110

Menezes, K. K., Nascimento, L. R., Ada, L., Polese, J. C., Avelino, P. R., and TeixeiraSalmela, L. F. (2016). Respiratory muscle training increases respiratory muscle strength and reduces respiratory complications after stroke: a systematic review. J. Physiother. 62, 138-144. doi: 10.1016/j.jphys.2016.05.014

Meyers, E. C., Kasliwal, N., Solorzano, B. R., Lai, E., Bendale, G., Berry, A., et al. (2019). Enhancing plasticity in central networks improves motor and sensory recovery after nerve damage. Nat. Commun. 10:5782. doi: 10.1038/s41467-01913695-0

Meyers, E. C., Solorzano, B. R., James, J., Ganzer, P. D., Lai, E. S., Rennaker, R. L., et al. (2018). Vagus nerve stimulation enhances stable plasticity and generalization of stroke recovery. Stroke 49, 710-717. doi: 10.1161/ STROKEAHA.117.019202

Mitchell, C., Bowen, A., Tyson, S., Butterfint, Z., and Conroy, P. (2017). Interventions for dysarthria due to stroke and other adult-acquired, nonprogressive brain injury. Cochrane Datab. Syst. Rev. 1:CD002088. doi: 10.1002/ 14651858.CD002088.pub3

Mitchell, C., Gittins, M., Tyson, S., Vail, A., Conroy, P., Paley, L., et al. (2020). Prevalence of aphasia and dysarthria among inpatient stroke survivors: describing the population, therapy provision and outcomes on discharge. Aphasiology 35, 950-960. doi: 10.1080/02687038.2020.1759772

Morris, G. L., and Mueller, W. M. (1999). Long-term treatment with vagus nerve stimulation in patients with refractory epilepsy. Neurology 53, 1731-1731. doi: 10.1212/WNL.53.8.1731

Morrison, R. A., Danaphongse, T. T., Abe, S. T., Stevens, M. E., Ezhil, V., Seyedahmadi, A., et al. (2021). High intensity VNS disrupts VNS-mediated plasticity in motor cortex. Brain Res. 1756:147332. doi: 10.1016/j.brainres.2021. 147332

Morrison, R. A., Danaphongse, T. T., Pruitt, D. T., Adcock, K. S., Mathew, J. K., Abe, S. T., et al. (2020). A limited range of vagus nerve stimulation intensities produce motor cortex reorganization when delivered during training. Behav. Brain Res. 391:112705. doi: 10.1016/j.bbr.2020.112705 
Morrison, R. A., Hulsey, D. R., Adcock, K. S., Rennaker, R. L., Kilgard, M. P., and Hays, S. A. (2019). Vagus nerve stimulation intensity influences motor cortex plasticity. Brain Stimul. 12, 256-262. doi: 10.1016/j.brs.2018.10.017

Naeser, M. A., Martin, P. I., Ho, M., Treglia, E., Kaplan, E., Bashir, S., et al. (2012). Transcranial magnetic stimulation and aphasia rehabilitation. Arch. Phys. Med. Rehabil. 93, S26-S34. doi: 10.1016/j.apmr.2011.04.026

Nichols, J. A., Nichols, A. R., Smirnakis, S. M., Engineer, N. D., Kilgard, M. P., and Atzori, M. (2011). Vagus nerve stimulation modulates cortical synchrony and excitability through the activation of muscarinic receptors. Neuroscience 189, 207-214. doi: 10.1016/j.neuroscience.2011.05.024

Noble, L. J., Gonzalez, I. J., Meruva, V. B., Callahan, K. A., Belfort, B. D., Ramanathan, K. R., et al. (2017). Effects of vagus nerve stimulation on extinction of conditioned fear and post-traumatic stress disorder symptoms in rats. Transl. Psychiatry 7:e1217. doi: 10.1038/tp.2017.191

Noble, S., and Benfield, P. (1998). Piracetam. CNS Drugs 9, 497-511. doi: 10.2165/ 00023210-199809060-00006

Pena, D. F., Childs, J. E., Willett, S., Vital, A., McIntyre, C. K., and Kroener, S. (2014). Vagus nerve stimulation enhances extinction of conditioned fear and modulates plasticity in the pathway from the ventromedial prefrontal cortex to the amygdala. Front. Behav. Neurosci. 8:327. doi: 10.3389/fnbeh.2014.00327

Permsirivanich, W., Tipchatyotin, S., Wongchai, M., Leelamanit, V., Setthawatcharawanich, S., Sathirapanya, P., et al. (2009). Comparing the effects of rehabilitation swallowing therapy vs. neuromuscular electrical stimulation therapy among stroke patients with persistent pharyngeal dysphagia: a randomized controlled study. J. Med. Assoc. Thai. Chotmaihet Thangphaet 92, 259-265.

Porter, B. A., Khodaparast, N., Fayyaz, T., Cheung, R. J., Ahmed, S. S., Vrana, W. A., et al. (2012). Repeatedly pairing vagus nerve stimulation with a movement reorganizes primary motor cortex. Cereb. Cortex 22, 2365-2374. doi: 10.1093/ cercor/bhr316

Pruitt, D. T., Danaphongse, T. T., Lutchman, M., Patel, N., Reddy, P., Wang, V., et al. (2021). Optimizing dosing of vagus nerve stimulation for stroke recovery. Transl. Stroke Res. 12, 65-71. doi: 10.1007/s12975-020-00829-6

Pruitt, D. T., Schmid, A. N., Kim, L. J., Abe, C. M., Trieu, J. L., Choua, C., et al. (2016). Vagus nerve stimulation delivered with motor training enhances recovery of function after traumatic brain injury. J. Neurotrauma 33, 871-879. doi: $10.1089 /$ neu. 2015.3972

Roosevelt, R. W., Smith, D. C., Clough, R. W., Jensen, R. A., and Browning, R. A. (2006). Increased extracellular concentrations of norepinephrine in cortex and hippocampus following vagus nerve stimulation in the rat. Brain Res. 1119, 124-132. doi: 10.1016/j.brainres.2006.08.048

Schlaug, G., Marchina, S., and Norton, A. (2009). Evidence for plasticity in white-matter tracts of patients with chronic broca's aphasia undergoing intense intonation-based speech therapy. Ann. N.Y. Acad. Sci. 1169, 385-394. doi: 10.1111/j.1749-6632.2009.04587.x

Seol, G. H., Ziburkus, J., Huang, S., Song, L., Kim, I. T., Takamiya, K., et al. (2007). Neuromodulators control the polarity of spike-timing-dependent synaptic plasticity. Neuron 55, 919-929. doi: 10.1016/j.neuron.2007.08.013

Singh, S. (2006). Dysphagia in stroke patients. Postgraduate Med. J. 82, 383-391. doi: 10.1136/pgmj.2005.043281

Sivaji, V., Grasse, D. W., Hays, S. A., Bucksot, J. E., Saini, R., Kilgard, M. P., et al. (2019). ReStore: a wireless peripheral nerve stimulation system. J. Neurosci. Methods 320, 26-36. doi: 10.1016/j.jneumeth.2019. 02.010

Smithard, D. G., Smeeton, N. C., and Wolfe, C. D. A. (2006). Long-term outcome after stroke: does dysphagia matter? Age Ageing 36, 90-94. doi: 10.1093/ageing/ afl149

Souza, R. R., Robertson, N. M., Mathew, E., Tabet, M. N., Bucksot, J. E., Pruitt, D. T., et al. (2020). Efficient parameters of vagus nerve stimulation to enhance extinction learning in an extinction-resistant rat model of PTSD. Prog. Neuro Psychopharmacol. Biol. Psychiatry 99:109848. doi: 10.1016/j.pnpbp.2019. 109848
Stipancic, K. L., Borders, J. C., Brates, D., and Thibeault, S. L. (2019). Prospective investigation of incidence and co-occurrence of dysphagia, dysarthria, and aphasia following ischemic stroke. Am. J. Speech-Lang. Pathol. 28, 188-194. doi: 10.1044/2018_AJSLP-18-0136

Strand, E. A., Duffy, J. R., Clark, H. M., and Josephs, K. (2014). The apraxia of speech rating scale: A tool for diagnosis and description of apraxia of speech. J. Commun. Disord. 51, 43-50. doi: 10.1016/j.jcomdis.2014.06.008

Terré, R., and Mearin, F. (2009). Resolution of tracheal aspiration after the acute phase of stroke-related oropharyngeal dysphagia. Am. J. Gastroenterol. 104, 923-932. doi: 10.1038/ajg.2008.160

Thiel, A., Hartmann, A., Rubi-Fessen, I., Anglade, C., Kracht, L., Weiduschat, N., et al. (2013). Effects of noninvasive brain stimulation on language networks and recovery in early poststroke aphasia. Stroke 44, 2240-2246. doi: 10.1161/ STROKEAHA.111.000574

Tseng, C.-T., Brougher, J., Gaulding, S. J., Hassan, B. S., and Thorn, C. A. (2020). Vagus nerve stimulation promotes cortical reorganization and reduces taskdependent calorie intake in male and female rats. Brain Res. 1748:147099. doi: 10.1016/j.brainres.2020.147099

Turkeltaub, P. E., Swears, M. K., D’Mello, A. M., and Stoodley, C. J. (2016). Cerebellar tDCS as a novel treatment for aphasia? Evidence from behavioral and resting-state functional connectivity data in healthy adults. Restorative Neurol. Neurosci. 34, 491-505. doi: 10.3233/RNN-150633

Tyler, R., Cacace, A., Stocking, C., Tarver, B., Engineer, N., Martin, J., et al. (2017). Vagus nerve stimulation paired with tones for the treatment of tinnitus: a prospective randomized double-blind controlled pilot study in humans. Sci. Rep. 7:11960. doi: 10.1038/s41598-017-12178-w

Vanneste, S., Martin, J., Rennaker, R. L., and Kilgard, M. P. (2017). Pairing sound with vagus nerve stimulation modulates cortical synchrony and phase coherence in tinnitus: an exploratory retrospective study. Sci. Rep. 7:17345. doi: 10.1038/s41598-017-17750-y

Wan, C. Y., Zheng, X., Marchina, S., Norton, A., and Schlaug, G. (2014). Intensive therapy induces contralateral white matter changes in chronic stroke patients with Broca's aphasia. Brain Lang. 136, 1-7. doi: 10.1016/j.bandl.2014.03.011

Wilson, S. M., and Schneck, S. M. (2021). Neuroplasticity in post-stroke aphasia: a systematic review and meta-analysis of functional imaging studies of reorganization of language processing. Neurobiol. Lang. 2, 22-82. doi: 10.1162/ nol_a_00025

Yang, J., and Phi, J. H. (2019). The present and future of vagus nerve stimulation. J. Korean Neurosurg. Soc. 62, 344-352. doi: 10.3340/jkns.2019.0037

Zuo, Y., Smith, D. C., and Jensen, R. A. (2007). Vagus nerve stimulation potentiates hippocampal LTP in freely-moving rats. Physiol. Behav. 90, 583-589. doi: 10. 1016/j.physbeh.2006.11.009

Conflict of Interest: MK has a financial interest in MicroTransponder Inc., which is developing VNS for stroke.

The remaining authors declare that the research was conducted in the absence of any commercial or financial relationships that could be construed as a potential conflict of interest.

Publisher's Note: All claims expressed in this article are solely those of the authors and do not necessarily represent those of their affiliated organizations, or those of the publisher, the editors and the reviewers. Any product that may be evaluated in this article, or claim that may be made by its manufacturer, is not guaranteed or endorsed by the publisher.

Copyright (c) 2021 Morrison, Hays and Kilgard. This is an open-access article distributed under the terms of the Creative Commons Attribution License (CC BY). The use, distribution or reproduction in other forums is permitted, provided the original author(s) and the copyright owner(s) are credited and that the original publication in this journal is cited, in accordance with accepted academic practice. No use, distribution or reproduction is permitted which does not comply with these terms. 